\title{
Simulation and experimental of oil-water flow with effect of heat transfer in horizontal pipe
}

\author{
Esam Mejbel Abed", Zahra'a Aamir Auda \\ Babylon University- College of Engineering, Mechanical Department, Babylon, Iraq \\ Email address: \\ dr.esammejbil@yahoo.com (Esam M. A.), zahraazahraa932@gmail.com (Zahra'a A. A.)
}

\section{To cite this article:}

Esam Mejbel Abed, Zahra'a Aamir Auda. Simulation and Experimental of Oil-Water Flow with Effect of Heat Transfer in Horizontal Pipe. International Journal of Mechanical Engineering and Applications. Vol. 2, No. 6, 2014, pp. 117-127. doi: 10.11648/j.ijmea.20140206.16

\begin{abstract}
There is a strong tendency for two immiscible fluids to arrange themselves so that the low viscosity constituent is in the region of high share. Therefore, it may be possible to introduce a beneficial effect in any flow of a very viscous liquid by introducing amount of a fluid lubricated as liquid-liquid oil-water flow. Two main classes of flows are seen, annular and small bubble in all experimental results. The pressure drop and mean heat-transfer coefficients were observed to depend strongly on the flow patterns. A correlation of the two-phase mean heat-transfer coefficients, based on a simple model of liquid flow, with a Reynolds number based on the actual mean velocity of the liquid mixture two-phase flow, were developed. An experimental rig facility has been designed and constructed, to enable measurements of local parameters in oil-water flow in the developing region of the flow in a $32 \mathrm{~mm}$ ID $6 \mathrm{~m}$ long pipe. The large discrepancies between model predictions and experimental data are reported in the literature review that the physics of oil-water flow is complex and not yet fully understood. The flow patterns that appear are classified in flow pattern maps as functions of either mixture velocity and water cut or superficial velocities. From these experiments a smaller number of annular flows are selected for studies of velocity and turbulence. The theoretical study was executed using software Fluent program, a modified turbulent diffusion model is presented. Simulation results carried out with the model show more physical predictions with respect to the particle deposition process and concentration profile. The theoretical results represent the pressure gradient distribution, velocity and mean heat transfer coefficient, pressure contours, velocity vectors, streamlines, and also velocity profiles. It was found that the methods with more restrictions (in terms of the applicable range of void fraction, liquid superficial Reynolds number) give better predictions.
\end{abstract}

Keywords: Two-Phase, Annular Flow, Flow Regime, Heat Transfer, CFD

\section{Introduction}

Oil-water two-phase flow widely exists in petroleum industry such as crude oil production and transportation through both horizontal and inclined pipes. During the simultaneous flow of two liquids there are several flow patterns. The occurrence of two and three phases flow in pipelines is very common in the petroleum industry.

The density difference between the two liquids has a substantial effect on the flow pattern. Two immiscible liquids of different densities tend to stratify when flowing in a pipeline. Thus, it is more difficult to produce a dispersed flow regime when the density difference is high. For low viscosities, the same flow patterns are observed when oils of different viscosities are used, but transition from one flow regime to another may appear at different superficial velocities. In general, the viscosity has a dual effect on the flow: (1) increasing viscosity can increase instability due to the different velocity profiles at the interface of the two layers, and (2) at the same time it helps to dissipate the energy that causes instability.

Lawrence and Panagiota studied liquid-liquid flows for stratified flow. The experimental data were obtained in a horizontal $14 \mathrm{~mm}$ ID acrylic pipe, for test oil and water superficial velocities ranging from $0.02 \mathrm{~m} / \mathrm{s}$ to $0.51 \mathrm{~m} / \mathrm{s}$ and from $0.05 \mathrm{~m} / \mathrm{s}$ to $0.62 \mathrm{~m} / \mathrm{s}$, respectively. Using conductance probes, average interface heights were obtained at the pipe center and close to the pipe wall, which revealed a concave interface shape in all cases studied. A correlation between the two heights was developed that was used in the two-fluid model. In addition, from the time series of the probe signal at the pipe center, the average wave amplitude was calculated to be $0.0005 \mathrm{~m}$ and was used as an equivalent roughness in the interfacial shear stress model [1].

The effect of viscosity, studied by Russell, et al. and 
Charles, et al., seems to have little or no effect on the observed flow patterns for oil-water flows [2],[3]. Glass carried out experiments for 1.2 meter long, $1 \mathrm{~cm}$ inner diameter tubing, in which the oil viscosity was varied from (10 to $30,000 \mathrm{cp}$ ), the oil gravity from $(0.97$ to 1.03$)$, the volumetric water fraction from $(0.09$ to 0.8$)$ and the superficial velocity of oil from $(0.06$ to 1.28$) \mathrm{m} / \mathrm{s}$, The indicated that the less viscous is the oil, the more is the core would tend to break up into globs of oil of various sizes [4]. Finally, Fujii, et al. studied in acrylic pipe $2.5 \mathrm{~cm}$ diameter, the oil viscosity was 61.5 and the density ratio 0.98 .The additional measurements pressure gradient, holdup water were performed .The observed flow patterns were stratified flow, stratified with mixing and with increasing in the flow rate the viscous core breakup to either large slugs and elongated bubble or spherical bubble [5].

The oil layer loses its continuity and moves as discrete droplets separated by the water continuous-phase. De Salve1, et al. used a wire mesh sensor, based on the measurement of the local instantaneous conductivity of the two-phase mixture has been used to characterize the fluid dynamics of the gasliquid interface in a horizontal pipe flow. Experiments with a pipe of a nominal diameter of $19.5 \mathrm{~mm}$ and total length of $6 \mathrm{~m}$, have been performed with air/water mixtures, at ambient conditions. The flow quality ranges from 0.00016 to 0.22 and the superficial velocities range from 0.1 to $10.5 \mathrm{~m} / \mathrm{s}$ for air and from 0.02 to $1.7 \mathrm{~m} / \mathrm{s}$ for water; the flow pattern is stratified, slug/plug and annular. A sensor with an inner diameter of 19.5 $\mathrm{mm}$ and a measuring matrix of $16 \times 16$ points equally distributed over the cross-section has been chosen for the measurements. From the analysis of the Wire Mesh Sensor digital signals the average and the local void fraction are evaluated and the flow patterns are identified with reference to space, time and flow rate boundary conditions [6].

Guzhov, et al. observed that the forward edge of the oil bodies is bent downward, probably by the action of the clockwise eddies. The water region turbulent energy tried to distribute larger oil droplets along the cross sectional area of the pipe, but the upward buoyancy prevails and a dispersion of oil in water over water layer is developed. With a further increase of the water superficial velocity, the frequency and intensity of water vortices increase, and more and smaller oil droplets are formed. Under these conditions, the dispersed oil in water flow pattern is formed [7].

The pressure drop in production pipelines has large impact on the design of a new field and on the operational costs. The pressure drop limits the maximum flow and is thus a critical parameter, both in terms of cost evaluations and production optimization. Panagiota, et al. studied the pressure drop measurement in oil and water pre wetted pipes for water and kerosene (Exxsol D80 with $801 \mathrm{~kg} / \mathrm{m} 3$ and density and 1.6 MPa.s viscosity), founding that at the lower velocity the flows are either dispersed or separated with inter-entrainment at the liquid-liquid inter-phase [8].

There are three types of heat transfer modes namely, convection, conduction, and radiation. In pipelines and wellbores, convective heat losses occur between flowing fluids and the pipe wall. In a typical convective heat transfer, a hot surface heats the surrounding fluid, which is then carried away by fluid movement. As mentioned earlier, many separate studies have been carried out to predict convective heat transfer for pipe flow in two-phase flow. Zimmerman, et al. studied experimentally air-water flow with heat transfer in a $25 \mathrm{~mm}$ internal diameter horizontal pipe. The water superficial velocity varied from $24.2 \mathrm{~m} / \mathrm{s}$ to $41.5 \mathrm{~m} / \mathrm{s}$ and the air superficial velocity varied from $0.02 \mathrm{~m} / \mathrm{s}$ to $0.09 \mathrm{~m} / \mathrm{s}$. The aim of the study was to determine the heat transfer coefficient and its connection to flow pattern and liquid film thickness. The flow patterns were visualized using a high speed video camera, and the film thickness was measured by the conductive tomography technique. The heat transfer coefficient was calculated from the temperature measurements using the infrared thermography method. It was found that the heat transfer coefficient at the bottom of the pipe is up to three times higher than that at the top, and becomes more uniform around the pipe for higher air flowrates [9]. Hetsroni, et al. performed experiments to study the flow regimes and heat transfer in air-water flow in $8 \theta$ inclined tubes of inner diameter of 49.2 and $25 \mathrm{~mm}$. The flow regimes were investigated by using high-speed video technique and conductive tomography. The thermal patterns on the heated wall and local heat transfer coefficients were obtained by infrared thermograph. Under the conditions studied, disturbance waves of different forms were observed. The analysis of the behavior of the heat transfer coefficients, together with flow visualization and conductive tomography sowed that dry out took place in the open annular flow regimes with motionless or slowly moving droplets [10].

Roula and Dash studied Pressure drop through sudden contraction in small circular pipes have been numerically investigated, using air and water as the working fluids at room temperature and near atmospheric pressure. Two-phase computational fluid dynamics (CFD) calculations, using Eulerian-Eulerian model with the air phase being compressible, are employed to calculate the pressure drop across sudden contraction. The pressure drop is determined by extrapolating the computed pressure profiles upstream and downstream of the contraction. The larger and smaller tube diameters are $1.6 \mathrm{~mm}$ and $0.84 \mathrm{~mm}$, respectively. Computations have been performed with single-phase water and air, and two-phase mixtures in a range of Reynolds number (considering all-liquid flow) from 1000 to 12000 and flow quality from $1.9 * 10^{-3}$ to $1.6 * 10^{-2}$. The contraction loss coefficients are found to be different for single-phase flow of air and water. The numerical results are validated against experimental data from the literature and are found to be in good agreement. Based on the numerical results as well as experimental data, a correlation is developed for two-phase flow, the pressure drop caused by the flow contraction [11].

Al-yaari and Abo-Sharkh investigated numerically, using commercial CFD package FLUENT 6.2 in horizontal pipe (0.0254), Oil-water stratified flow regime is simulated using Volume of Fluid (VOF) multiphase flow approach. RNG k-E turbulence model is adopted. Mesh independent study has 
been achieved to decide on the mesh size. The phase separation is investigated for the tested stratified flow points. CFD Numerical simulation predicted the stratified flow pattern and smoothness and the type of the interface. On the other hand, while the oil layer was clearly predicated by the CFD model, water layer was not clearly predicted as a clear segregated layer [12].

\section{Experimental Apparatus and Procedure}

The analysis performed on experimental laboratory data; provides the main source of information about specific twophase flow regimes. This research presents a detailed description of the experimental rig used to study the oilwater annular flow with heat transfer in horizontal pipe. A liquid-liquid flow facility has been built to study phenomenon of two- phase flow with heat transfer in pipe in the experimental rig. The experimental rig is build up within the fluid laboratories of the Mechanical Engineering Department at University of Babylon. The physical properties of the system, the criteria of experimental design and the operational principle of each instrument are explained. The experimental facility consists of a main pipe flow test section made from $32 \mathrm{~mm}$ inner diameter and $6 \mathrm{~m}$ length. A $2 \mathrm{~m}$ Perspex manufactured from methyl methacrylate monomers. A $2 \mathrm{~m}$ pvc, Polyvinyl chloride (C4H8) is the most widely used of any of thermoplastics, the specification of pvc is (20-630)mm OD (6)m length (2$30) \mathrm{mm}$ thickness, and $2 \mathrm{~m}$ copper pipe of $32 \mathrm{~mm}$ diameter with a circular cross section area. The test section is a $0.6 \mathrm{~m}$ long at a distance of $4 \mathrm{~m}$ from entry. For imaging the flow of clear use lighting system consists of a two fluorescent lamp number two in beside camera. The system is equipped with a diffusive white surface in front of the lamp for greater light uniformity. The rigid steel frame supporting the test pipe section is constructed to fix the pipes with no vibration as shown in Fig.(1a,b). The experiments are carried out at ambient laboratory conditions of approximately $25^{\circ} \mathrm{C}$ temperature and pressure of $1 \mathrm{bar}$. The experimental work includes two flow case liquid-liquid with and without heat transfer effect. The physical properties of the fluids used in the experiments are as shown in Table (1). The experiments two-phase liquid-liquid horizontal flow system are explained to investigation annular liquid-liquid flow through flow with heat(36 EXP.).

Table (1). Fluid properties

\begin{tabular}{lll}
\hline Product name & Oil & Water \\
\hline Density & $820 \mathrm{Kg} / \mathrm{m}^{3}$ & $1000 \mathrm{Kg} / \mathrm{m}^{3}$ \\
Viscosity & $1.52 * 10^{-3} \mathrm{Kg} / \mathrm{s} . \mathrm{m}$ & $0.89 * 10^{-3} \mathrm{~kg} / \mathrm{s} . \mathrm{m}$ \\
Surface Tension & $27.6 \mathrm{mN} / \mathrm{m}$ at $25^{\circ} \mathrm{C}$ & $71.99 \mathrm{~N} / \mathrm{m}$ \\
Oil-Water interfacial tension & $44.69 \mathrm{~m} . \mathrm{N} / \mathrm{m}$ at $25^{\circ} \mathrm{C}$ & $44.69 \mathrm{~N} / \mathrm{m}$ \\
\hline
\end{tabular}

\section{Experiments Limitation}

A flow can be laminar in the beginning for the passage of water only and then the flow convert to the turbulent case at passage the oil fluid. It is found that a flow in a pipe is laminar if the Reynolds number based on diameter of the pipe is less than 2000 and is turbulent if it is greater than 4000. Transitional flow prevails between these two limits. Reynolds number for turbulent flow is [13].

$$
\operatorname{Re}=\left(\rho_{\mathrm{m}} \cdot \mathrm{U}_{\mathrm{m}} \cdot \mathrm{D}\right) / \mu_{\mathrm{m}}
$$

The entrance length required for fully developed velocity profile to form laminar and turbulent flow respectively:

$$
\begin{gathered}
\text { For laminar flow } \mathrm{Le}=0.06 \mathrm{D} \mathrm{Re} \\
\text { For turbulent flow } \mathrm{Le}=4.4 \mathrm{D} \mathrm{Re}^{1 / 6}
\end{gathered}
$$

For present work and according to the pipe diameter, higher velocity of the liquid-liquid phase, the entrance length is $0.8723 \mathrm{~m}$ as equation (3). Therefore, the design of the experimental set-up carried out for pipe according to the maximum entrance length. The most physically based explanation is that:

Superficial Velocities and flow rates, the flow rate and superficial velocity of the fluid flow was measured as follows. The liquid flow rate is read directly from the float flow meter in $(1 / \mathrm{min})$, while the superficial velocity determined from the following equation as:

$$
\mathrm{Q}=\mathrm{Us} * \mathrm{~A}
$$

When $\mathrm{A}$ is the cross section area (the diameter of the entrance pipe for water equal to $(\mathrm{Dw}=11.2 \mathrm{~mm})$ and the entrance pipe for oil equal to $(\mathrm{Do}=23.2 \mathrm{~mm})$ ) and $\mathrm{Us}$ is the mixture velocity equal to the summation of the water and oil velocity.

The inlet water cut is defined by dividing the flow rate of water, $Q_{w}$, by the sum of flow rate of water and oil, $Q_{w}+Q_{g}$, as:

$$
\lambda=\frac{\mathrm{w}}{\mathrm{Qw}+\mathrm{Qo}}
$$

The mean heat-transfer coefficients $\left(\mathrm{h}_{\mathrm{TP}}\right.$ for the two-phase flow were calculated experimentally as reported by reference [14]:

$$
\begin{gathered}
\text { hTPEXP }=\frac{1}{\mathrm{~L}} \int \mathrm{h} \mathrm{dZ}=\frac{1}{\mathrm{~L}} \sum_{\mathrm{K}=1}^{\mathrm{NST}} \mathrm{hK} \Delta \mathrm{ZK} \\
\text { Where } Q=h A \Delta T \text {,then } \\
\text { hTPEXP }=\frac{1}{L} \sum_{K=1}^{N S T}\left(\frac{Q}{A(T w-T b)}\right) \Delta Z K
\end{gathered}
$$

Where $\mathrm{h}$ is the local mean heat transfer coefficient, $\mathrm{L}$ is the length of the test section, $\mathrm{k}$ is the index of the thermocouple stations, NST is the number of the thermocouple station, and $\Delta \mathrm{z}$ is the distance between each thermocouple and equal to 1 $\mathrm{m}$. $\mathrm{Q}$ is heat flux supply. A is the cross section area. Tb is the bulk temperature in each thermocouple station, which equal the temperature recorded by temperature recorder with SD card data logger with time. Tw is the wall temperature of test section. 
The wall shear stress, the mean shear stress at the wall for Newtonian and non-Newtonian fluids and for all flow regimes is given by reference [15]:

$$
\tau_{\mathrm{w}}=\frac{D}{4} \frac{\Delta p}{\Delta \times}
$$

\section{Simulation Work}

Two-phase oil-liquid annular flow is simulated in this work using the commercial CFD code FLUENT 6.3.26 in order to solve the governing equations. The problem considers the transient tracking of a oil-liquid interface. The working fluids are water and oil, and in order to develop an applicable analysis of the flow field on fluent 6.3.26 inclusively in ANSYS CFD.

\subsection{Mesh Generation}

The partial differential equations of fluid flow are not usually amenable to analytical solutions, except for very simple cases. Therefore, in order to analyze fluid flows, flow domains are split into smaller sub domains called elements or cells and the collection of all elements is known as mesh or grid. The governing equations are solved inside each of these portions of the domain. Care must be taken to ensure proper continuity of solution across the common interfaces between two sub domains, so that the approximate solutions inside various portions can be put together to give a complete picture of fluid flow in the entire domain. Grid generation is often considered as the most important and most time consuming part of CFD simulation as shown in fig. 2 .

\subsection{Governing Equations}

The fundamental governing equations of fluid dynamics in the theoretical work are continuity and momentum Equations in three dimensional.

\subsubsection{Conservation of Mass}

$$
\frac{\partial}{\partial t} \alpha_{\mathrm{q}} \rho_{\mathrm{q}}+\nabla \cdot \alpha_{\mathrm{q}} \rho_{\mathrm{q}} \vec{u}_{\mathrm{q}}=\sum_{p=1}^{n} \dot{m}_{\mathrm{pq}}
$$

\subsubsection{Conservation of Momentum}

$$
\begin{gathered}
\frac{\partial}{\partial t} \alpha_{\mathrm{q}} \rho_{\mathrm{q}} \vec{u}_{\mathrm{q}}+\nabla \cdot\left(\alpha_{\mathrm{q}} \rho_{\mathrm{q}} \vec{u}_{\mathrm{q}} \otimes \vec{u}_{\mathrm{q}}\right)=-\alpha_{\mathrm{q}} \nabla \mathrm{p}+\nabla \cdot \alpha_{\mathrm{q}} \overline{\bar{\tau}}_{\mathrm{q}}+\alpha_{\mathrm{q}} \rho_{\mathrm{q}} \vec{F}_{\mathrm{q}}+ \\
\sum_{p=1}^{n}\left(\mathrm{R}_{\mathrm{pq}}+\dot{m}_{\mathrm{pq}} \vec{u}_{\mathrm{pq}}\right.
\end{gathered}
$$

\subsubsection{Conservation of Energy}

$$
\begin{gathered}
\frac{\partial}{\partial t}\left(\alpha_{\mathrm{q}} \rho_{\mathrm{q}} \mathrm{h}_{\mathrm{q}}\right)+\nabla \cdot\left(\alpha_{\mathrm{q}} \rho_{\mathrm{q}} \vec{u}_{\mathrm{q}} \mathrm{h}_{\mathrm{q}}\right)=-\alpha_{\mathrm{q}} \frac{d p q}{d t}+\bar{\tau}_{\mathrm{k}}: \nabla \vec{u}_{\mathrm{q}}-\nabla \cdot \vec{q}_{\mathrm{q}}+\mathrm{s}_{\mathrm{q}}+ \\
\sum_{p=1}^{n}\left(\mathrm{Q}_{\mathrm{pq}}+\dot{m}_{\mathrm{pq}} \mathrm{h}_{\mathrm{pq}}\right)
\end{gathered}
$$

\subsection{Boundary Condition Application}

The boundary domain in the present problem is dependent on flow variables at the domain boundaries Specify fluxes of mass, momentum, energy, etc. into the domain. Defining boundary conditions involves: Identifying the location of the boundaries (e.g., inlets, walls, symmetry). Also, the turbulence kinetic energy $\mathrm{k}$ and its dissipation rate $\varepsilon$ initial guess those are estimated with the following equations according to Launder and Spalding [16]:

$$
\begin{gathered}
\mathrm{K}=3 / 2 \mathrm{I}^{2} \mathrm{Uin} 2 \\
\varepsilon=2 \mathrm{~K}_{\mathrm{in}}^{3 / 2} / \mathrm{d}
\end{gathered}
$$

The turbulence intensity for fully developed pipe flow is:

$$
\mathrm{I}=0.16 \mathrm{Re}_{-}{ }^{1 / 8}
$$

\section{Results and Discussion}

The experimental and theoretical work results are illustrated in the present section, which include the results obtained for pressure reading, inlet water cut, shear stress, viscosity and the effect of heat on the pressure as well as calculate the mean heat transfer coefficient with applied three thermal loads by using thermal heaters "eight finger shape" with a capacity of 2000 watt per heater for oil-water for different flow rates is presented.

\subsection{Experimental Result}

\subsubsection{Flow Visualization}

The first and simplest approach to study two-phase flow behavior in deviated pipes is to visualize the flow. Flow patterns play very important roles in two-phase flow to explain the phenomena of two-phase flow. Each regime has certain hydrodynamic characteristics, occurrence in nature and many applications in industries. It is clarify the form of flow with the effect of the heat, Fig. (3) shows an instantaneous side view of oil-water flow into the pipe, obtained by high speed video camera (AOS imaging studio v3). The flow is from the left to the right, the distance in the flow direction, shown in this image is $\mathrm{L}=60 \mathrm{~mm}$, to show the effect of heat transfer on the flow fluids applying power of the amount of 8000 watt and the rate of flow of the oil ranges from 5 to 10 liters per minute and the rate of flow of water ranging from 5 to 15 liters per minute by using the video system. Noting change the type of flow-type annular to type small bubbles due to decrease viscosity, which decreased with increasing temperature as shown in Fig.(3) bubbles of oil mediates the flow of water.

\subsubsection{Pressure Gradient}

The pressure drop in oil-water flow is dependent on flow pattern conditions. After applying the thermal heater loading with various value of heat flux from (4000) watt to (12000) watt for three values of water flow rate and four values of oil flow rate. Applying the second thermal load with the heat flux equal 8000 watt. Fig.(4) represents the relation between the pressure gradient and oil superficial velocity for various water superficial velocity. The pressure gradient increases with increasing the mixture velocity. Fig.(5),(6) and (7) show the pressure versus tap locations ( $11, \mathrm{x} 2, \mathrm{x} 3, \mathrm{x} 4$ and $\mathrm{x} 5)$. The pressure decreasing gradually until reach minimum value at the end of the pipe. Fig.(8) represents the pressure gradient 
fluctuation along the pipe with heat transfer effect, for oil flow rate equal $40 \mathrm{l} / \mathrm{min}$ and water flow rate equal 10,15 and $20 \mathrm{l} / \mathrm{min}$. It is show that the pressure gradients reading fluctuate with time due to two-phase effect. The pressure sensor recorded the pressure with time for five taps located along the pipe, and the pressure increased-decreased with time.

\subsubsection{Mean Heat Transfer Coefficient}

Fig.(9),(10) and (11) show variation of the overall mean heat transfer coefficient with the mixture Reynolds number. The mean heat transfer coefficient increase with increasing the mixture Reynolds number at the same power load. So, it's increased until reach maximum value when Reynolds number equal to 65125 for water superficial equal $20 \mathrm{l} / \mathrm{min}$ and power 12000 watt. It's noted that the mean heat transfer coefficient increased with increased the power until reach maximum value at $80.234 \mathrm{kw} / \mathrm{m}^{2} . \mathrm{k}$ when power equal 12000 watt.

Fig.(12) shows the bulk temperature readings along section for thermocouple stations. It's noted that the bulk temperature increase with increasing distance along the pipe until reach maximum value at the end of the pipe, for the same mixture flow rate. Also increase with increasing mixture flow rate for the same position.

Fig.(13) describes the relationship between the overall mean heat transfer coefficient values in all thermocouples station versus oil superficial velocity, These were calculated through every run for water superficial velocity from 1.69 to $3.38 \mathrm{~m} / \mathrm{s}$, and oil superficial velocity from 0.39 to $1.58 \mathrm{~m} / \mathrm{s}$. The mean heat transfer coefficient increases with increased oil due to decreasing the bulk and wall temperature as a result of increased oil velocity and thermal insulator.

\subsubsection{Effect Inlet Water Cut $\lambda$}

Average inlet water cut at least gradually from 0.2 to 0.5 when the speed of the water equal to $1.69 \mathrm{~m} / \mathrm{s}$., also from 0.2727 to 0.6 at the speed of water equal to $2.54 \mathrm{~m} / \mathrm{s}$ finally from 0.3333 to 0.6666 at the speed of water equal $3.38 \mathrm{~m} / \mathrm{s}$. Fig.(14) shows the water cut profiles measured for the experimental matrix conditions.

As can be seen, the water tends to settle at the bottom of the pipe, resulting a small difference in the measured water cut. At inlet water cut indicating slow settling of water droplets. The fact that the water cut is not zero at the oil rich layer at any data set indicates that the flow in the developing region.

\subsubsection{Shear Stress $\left(\tau_{w}\right)$}

Fig.(15) presents the wall shear stress versus mixture Reynolds number for different mixture superficial velocity with variable heating load (4000, 8000 and 120000) watt respectively, it's noted the wall shear stress increases with increasing the power applied and increasing the mixture velocity.

\subsubsection{Viscosity $\mu$}

The quantity of " $\mu$ " is called the viscosity, which is a property of the fluid. It is an indication of how much internal friction is present. Some fluids, such oils, have high viscosity, and a substantial applied stress is required to cause these fluids to flow. Other fluids, such as water, have lower viscosity and flow more easily for the same applied stress. In general, liquid viscosity decreases exponentially with increasing temperature, but gas viscosity increases with temperature. It's often varies considerably with temperature, and that effect must be considered in calculations. Fig.(16) shows the dynamic viscosity versus different temperature that resulted from applied three heating loads for different water velocity a fixed oil velocity.

\subsection{Simulation Results}

The brief literature review presented at the beginning of the chapter two reveals that additional work is required for establishing computational procedures leading to reliable predictions of oil-water annular flow. Available oil-water annular pipe flow experimental data are used to test the simulations obtained by FLUENT to study distribution phase, pressure, speed and shear stress. This shows that the Fluent depends on the mixture velocity and void fraction. These trials were used to match precisely with the terms of the annular flow that has been studied, which was extracted in practice.

Fig.(17) represents the mesh that has been applied to the geometry and the number of cells, 5000 .

Fig.(18) displays the small bubble that obtained after practice the condition and complete the iteration which lasted for more than 24 hours after the reduction of the system to reduce the iteration required and the time needed.

\subsubsection{Mean Heat Transfer Coefficient and Bulk Temperature}

Fig.(19) shows the heat transfer coefficient when the amount of power load 8000 watts. Note the increased heat transfer coefficient gradually due to increasing temperatures over time and this increase also produces a proven rate of ability and proven a flow rate of water used a $20 \mathrm{l} / \mathrm{m}$ with the gradient of the values of the rate of oil, which ranges from 10 to $40 \mathrm{l} / \mathrm{m}$ so the oil is heated at a higher rate of water and thus increases coefficient heat Transfer.

Fig.(20) represents the bulk temperature change versus oil superficial velocity, it's be the highest value when the flow rate of the oil equal to $20 \mathrm{l} / \mathrm{m}$ and then begin a downward as result of temperature stability to refer again overpaid when flow rate of oil increases to $40 \mathrm{l} / \mathrm{m}$.

\section{Comparison Experimental and Theoretical Results}

Comparing the results is important to determine the percentage of error between them and the reasons for the difference between the two results. The comparison also shows the existence of the causes leading to the inaccuracy of the practical results, including leaking pipes, flow meter or 
oil rate may be re-used when each experiment contains a proportion of the water. This comparison between the theoretical and practical results will be interpreted in the following section.

\subsection{Heat Transfer Effect}

Comparisons are presented on mean heat transfer coefficient and bulk temperature. Fig.(21) presents comparisons between the model predictions and the measured data for the effect of oil superficial velocity on the mean heat transfer coefficient along the pipe at power load equal to 8000 watt and water superficial velocity equal to $3.38 \mathrm{~m} / \mathrm{s}$. It can be observed that the model predictions follow trend of the data fairly well and the theoretical mean heat transfer effect coefficient has similar behavior as the experiments. Fig.(22) illustrates the bulk temperature versus oil superficial velocity, it can be observed that bulk temperature changed continuously with dependent on oil superficial velocity until reach maximum to $(24.91){ }^{\circ} \mathrm{C}$ at $\mathrm{Uo}$ equal to $(0.79) \mathrm{m} / \mathrm{s}$.

The percentage theoretical heat transfer coefficient decreases over experimental heat transfer coefficient are $6 \%$.

\section{Conclusion}

1 The work reveals that the annular flow regime exists over a wider range of phase flow rates. As a result, regime maps and transition equations available for gasliquid cases cannot be used as such to predict the patterns in liquid -liquid flows.

2 Pressure drop along the pipe was direct proportional for changes in oil-water superficial velocities.

3 Mean heat transfer coefficient increases with increasing heat flux that used in experimental work and its decreases with increasing in mixture superficial velocity. Finally, it's increased with wall temperature.

4 Void fraction has reverse behavior to that of hold up to wards changes in liquid superficial velocities and towards other flow characteristics.

5 CFD calculations using Fluent 6.3.26 were performed to predict the oil-water annular flow.

6 A model for the calculation of fully-developed, turbulent-turbulent oil-water annular flow in horizontal pipe is presented. The model is based on a numerical solution of the basic governing differential equations using a finite-volume method in a bipolar coordinate system, applying a simple mixing-length turbulence model. The moving wall assumption was implemented for the prediction of the interface behavior.

7 Volume of fluid (VOF) multiphase model with RNG-k$\varepsilon$ two equations turbulent model was selected among other different multiphase and turbulent models based on the convergence, prediction of the oil-water annular flow pattern and the smoothness of the interface.

8 Care should be taken while initializing the CFD solver to obtain convergence.

9 Mesh independent study has been achieved to decide on the optimum mesh size to be used in the simulation process.

10 The volume fraction value specified the phase inversion point which determined which of the two liquids dispersed in the other.

11 In this study water dispersed in oil for volume fractions less than 0.6 which represents the inversion volume fraction at which the oil began to dispersed in water.

12 All simulations give good agreement with the expected flow regime annular.

13The numerical model solves the resulting set of algebraic equations in an iterative way, simultaneously for both oil and water layers. The pressure gradient is calculated based on the condition that the velocity field in both layers must satisfy the total flow rate.

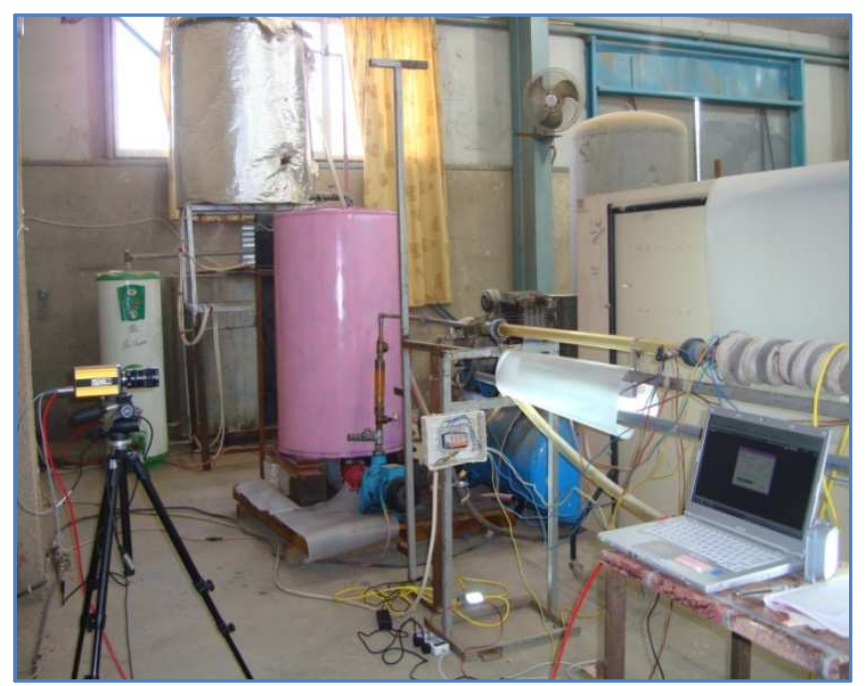

Fig. 1a. The experimental rig. 


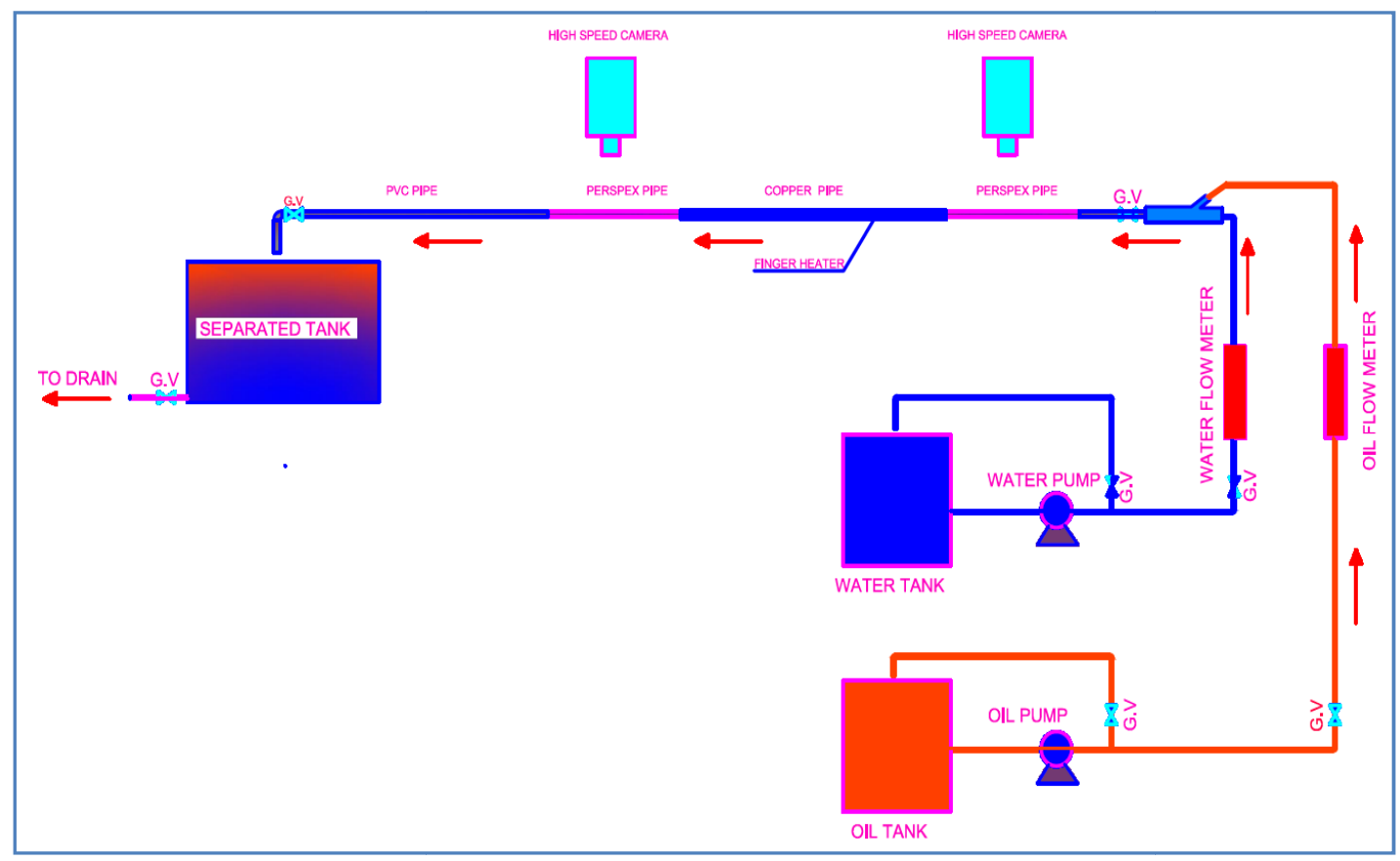

Fig. $1 \mathbf{b}$. The schematic of the experimental rig.

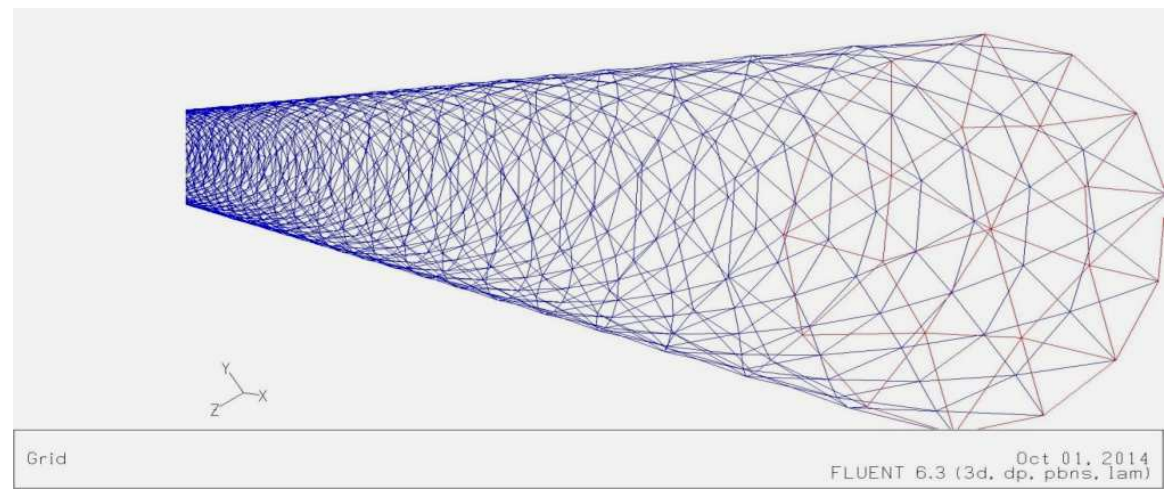

Fig. 2. the approach mesh used to create the pipe geometry.

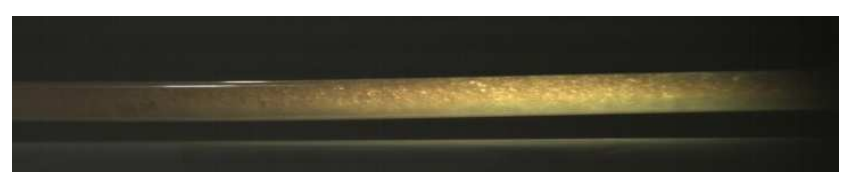

A Uo $=0.197 \mathrm{~m} / \mathrm{s}, \mathrm{Uw}=1.69 \mathrm{~m} / \mathrm{s}$

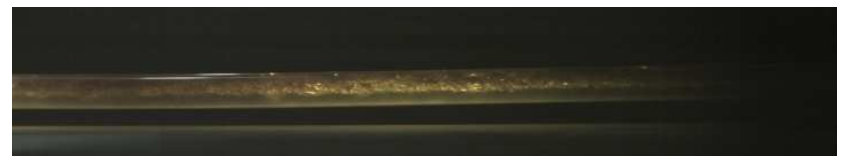

B Uo=0.197 m/s, Uw=2.54 m/s

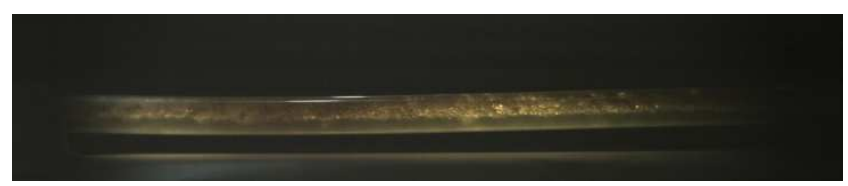

C Uo= $0.197 \mathrm{~m} / \mathrm{s}, U w=3.38 \mathrm{~m} / \mathrm{s}$

Fig. 3. Flow visualization at $Q o=5 \mathrm{l} / \mathrm{m}$ and $Q w=10,15,20 \mathrm{l} / \mathrm{m}$ at power load equal to 8000 watt.

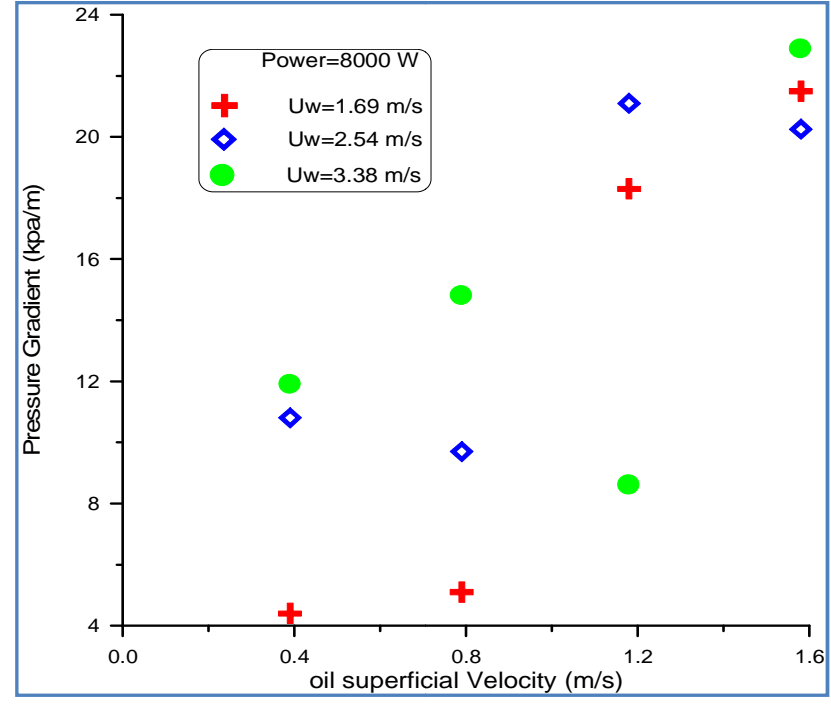

Fig. 4. shows the relation between the pressure gradient and oil velocity at power $=8000$ watt. 


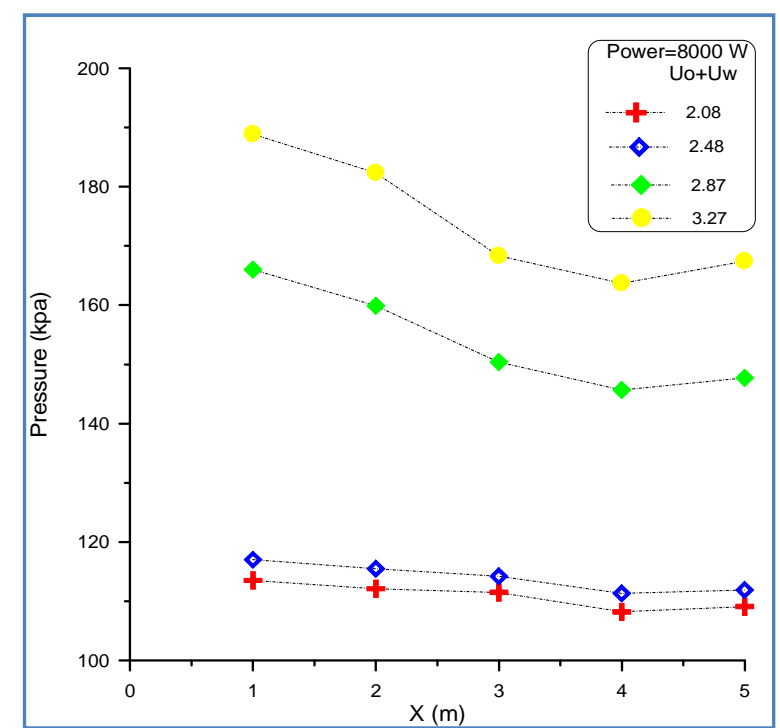

Fig. 5. Pressure reading of the different sensors along the pipe.

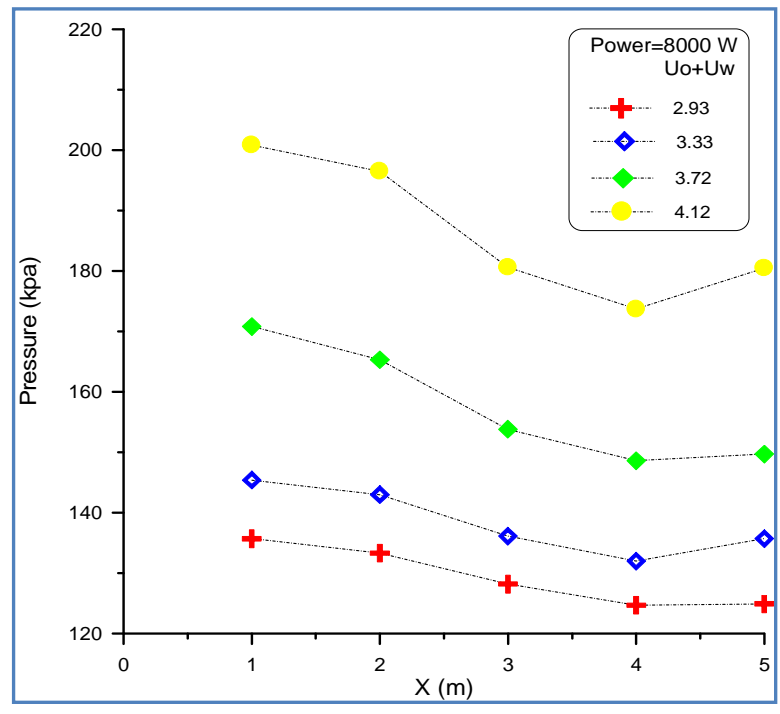

Fig. 6 Pressure reading of the different sensors along the pipe.

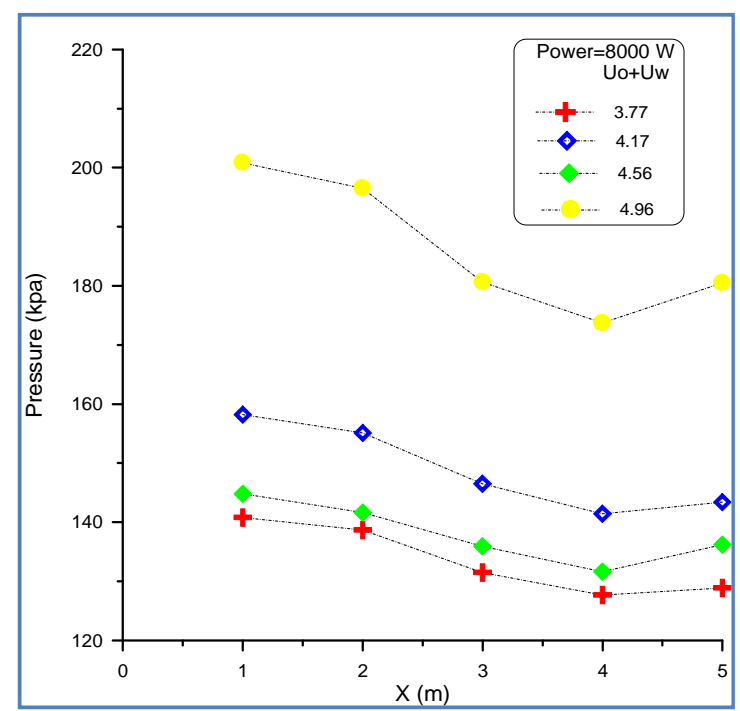

Fig. 7. Pressure reading of the different sensors along the pipe from.

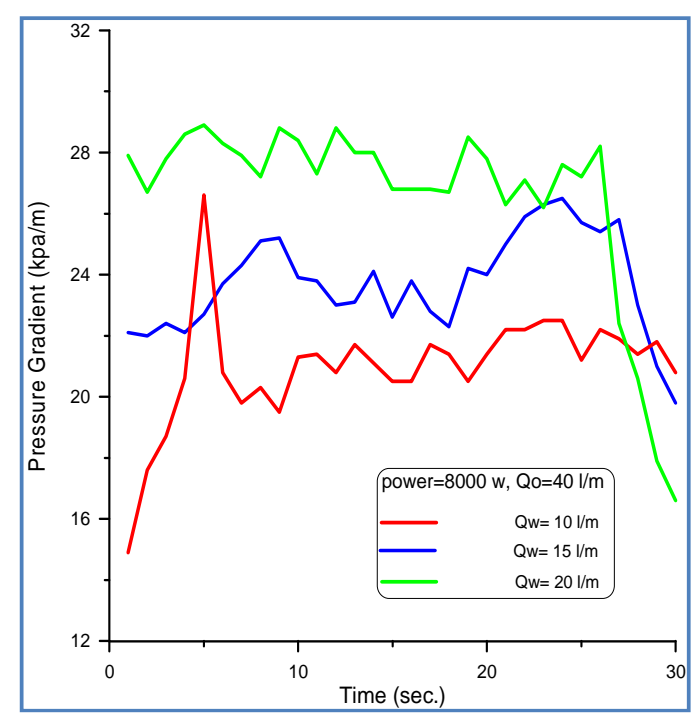

Fig. 8. Effect of Time evolution of Pressure obtained by Experimental.

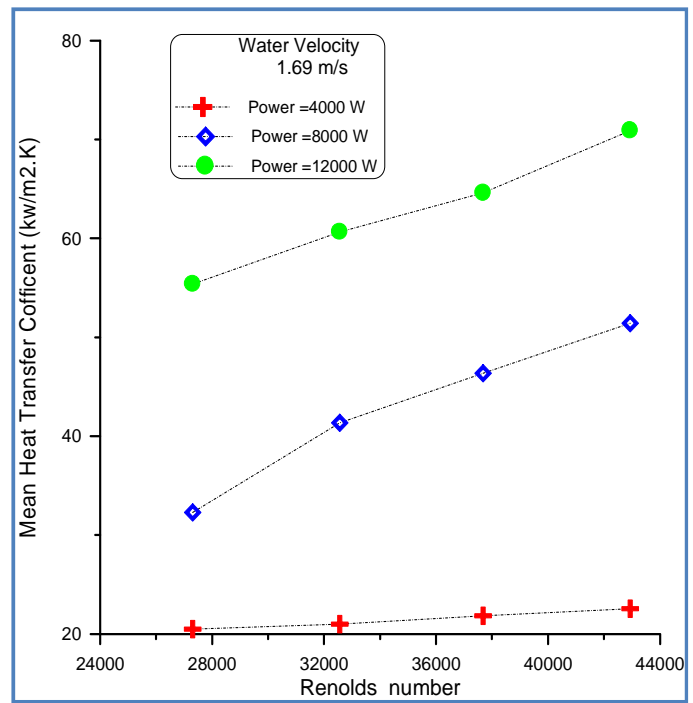

Fig. 9. Variation of the overall mean heat transfer coefficient with the mixture Reynolds number for various power.

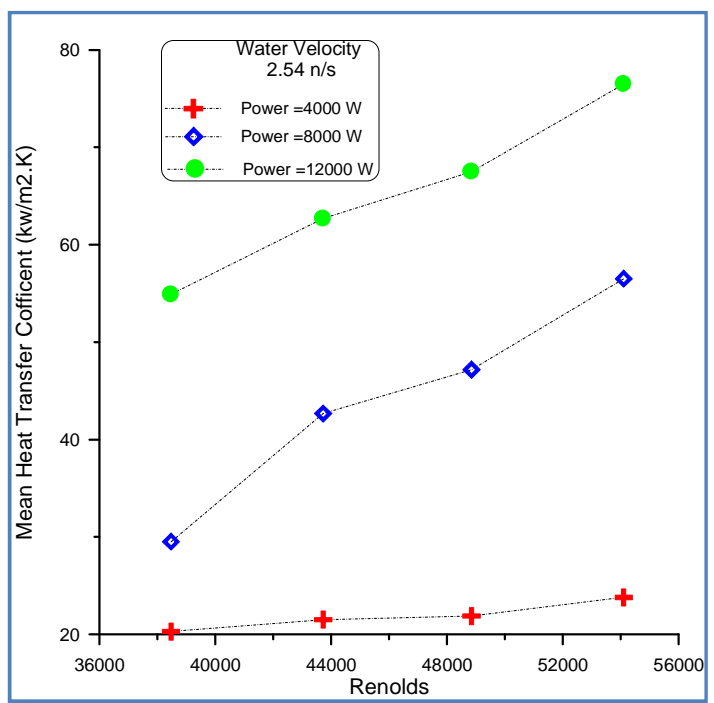

Fig. 10. Variation of the overall mean heat transfer coefficient with the mixture Reynolds number for various power. 


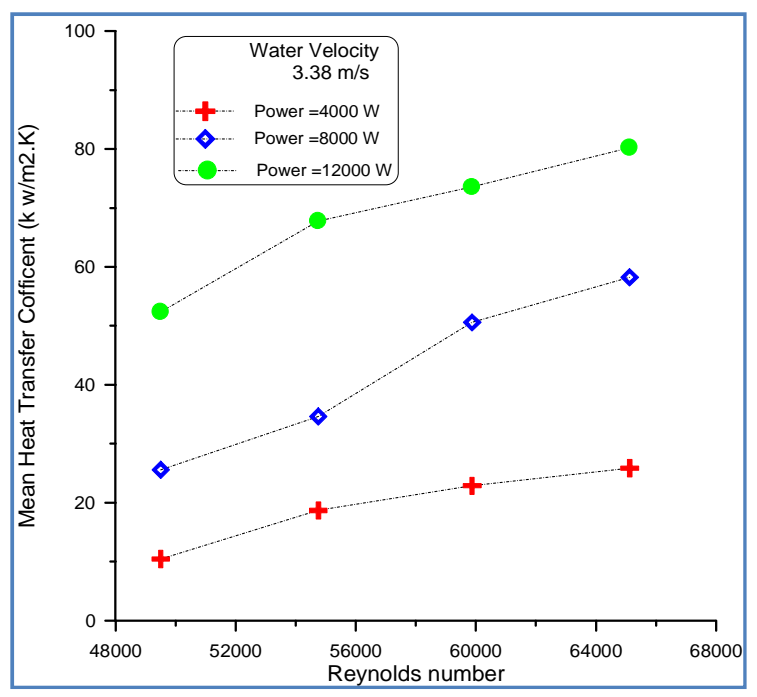

Fig. 11. Variation of the overall mean heat transfer coefficient with the mixture Reynolds number for various power.

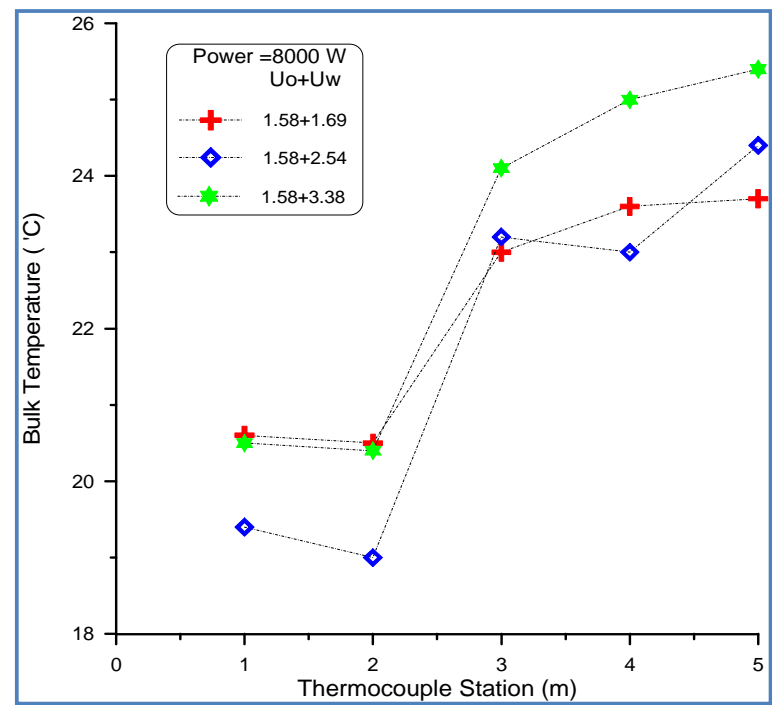

Fig. 12. Bulk Temperature distribution along the pipe.

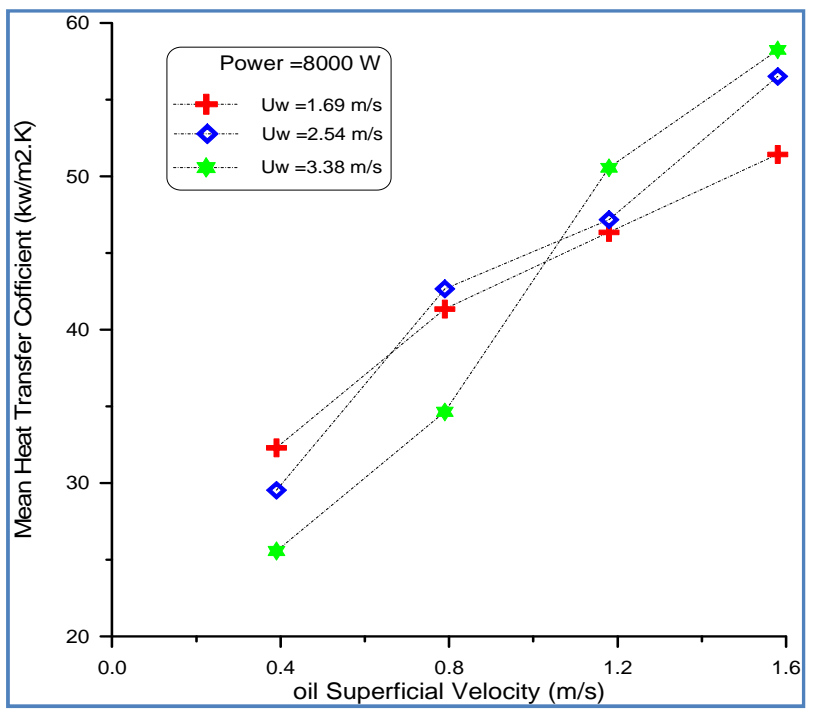

Fig. 13. Effect the mean heat transfer coefficient with oil-water two-phase flow.

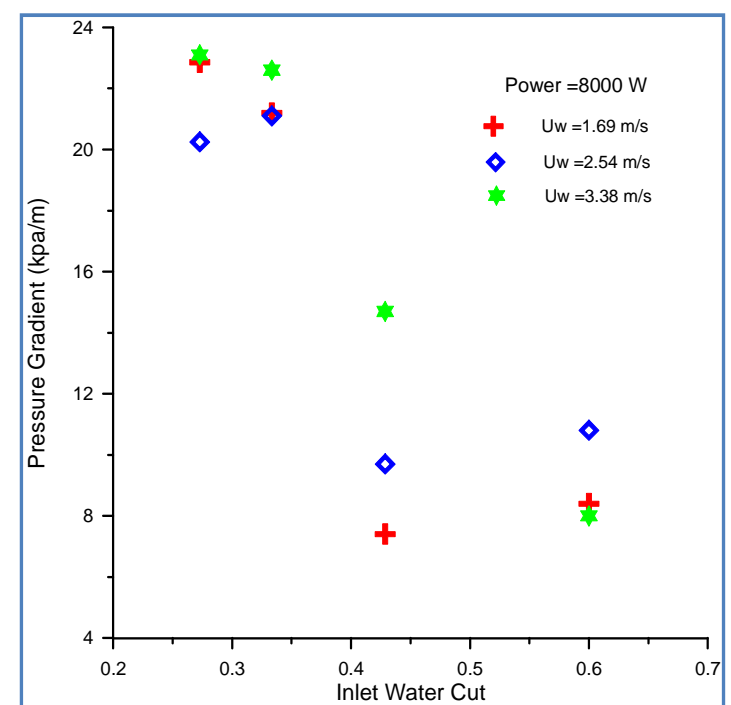

Fig. 14. Effect inlet water cut on the pressure gradient

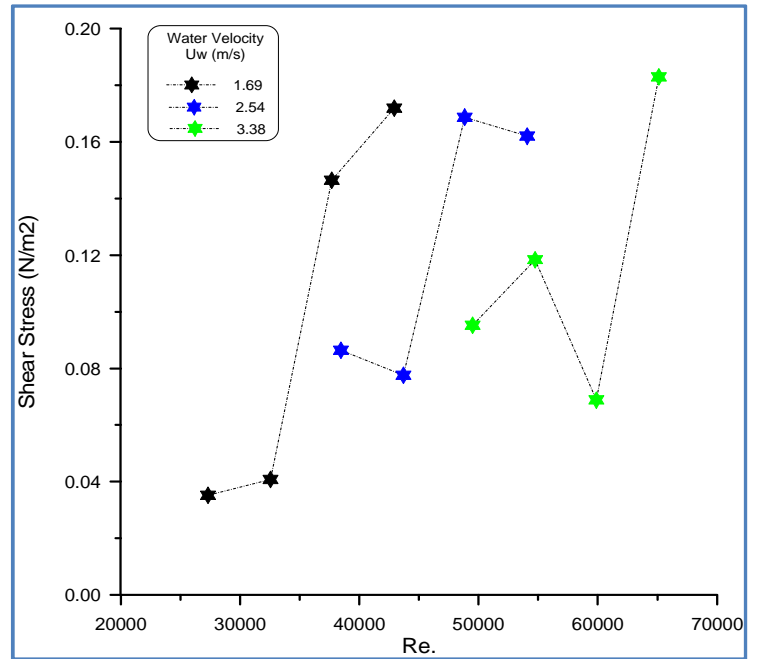

Fig. 15. Effect of Reynolds number on shear stress at wall for different water superficial velocity at power 8000 watt.

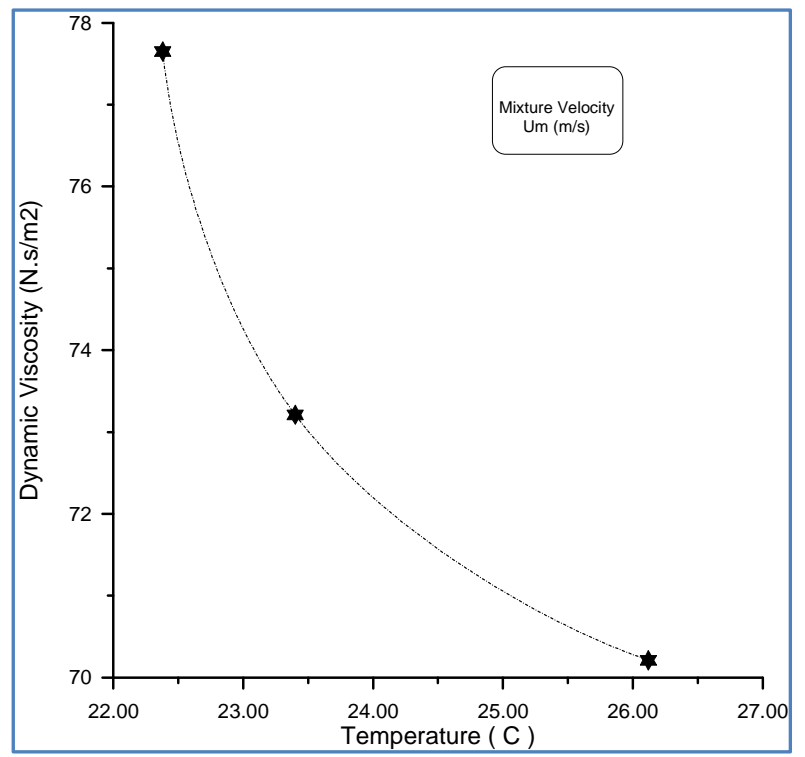

Fig. 16. Effect the temperature on dynamic viscosity. 

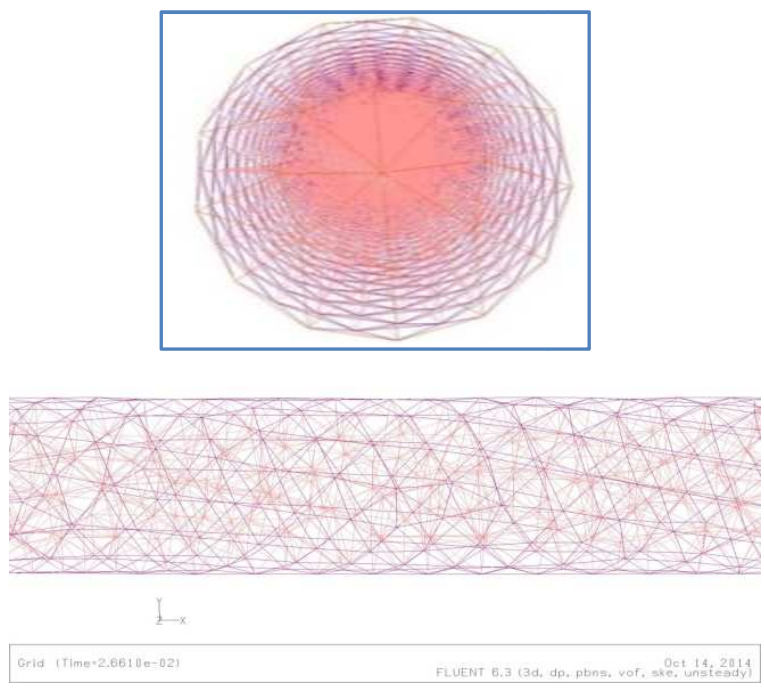

Fig. 17. Represent the pipe geometry of computational flow domain.

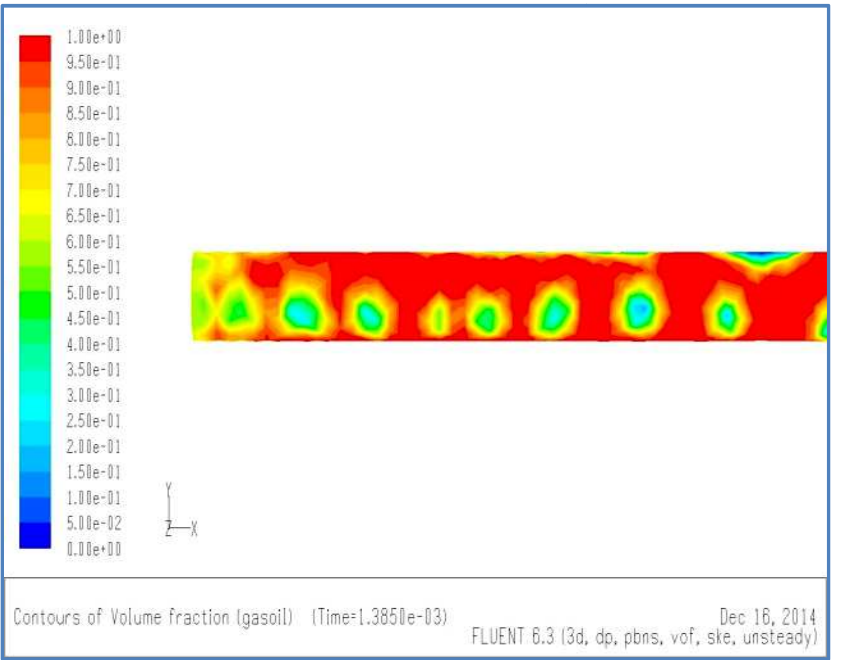

Fig. 18. Flow distribution V.F 0.6, Um $4 \mathrm{~m} / \mathrm{s}$.

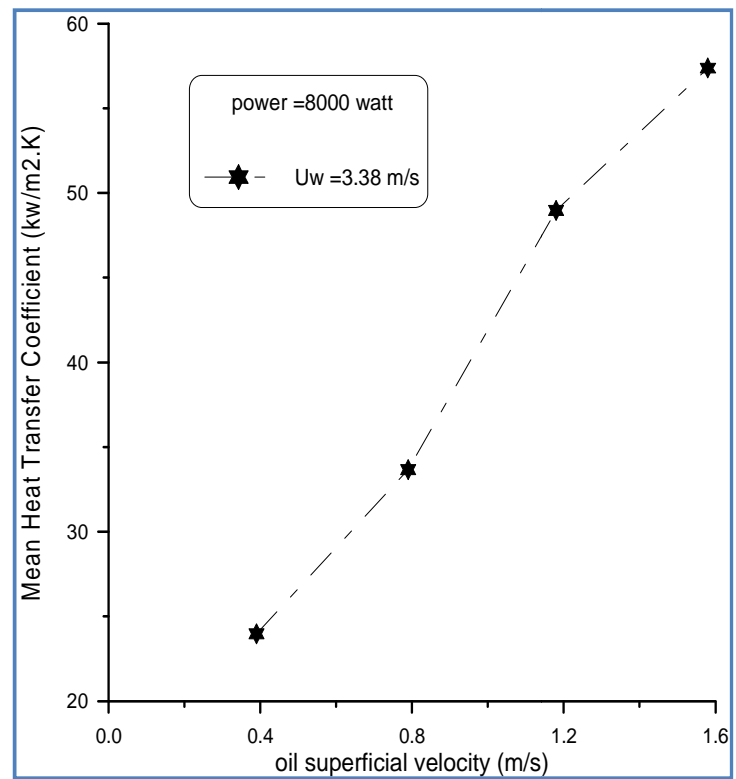

Fig. 19. Mean Heat Transfer Coefficient versus oil superficial velocity at power equal to 8000 watt.

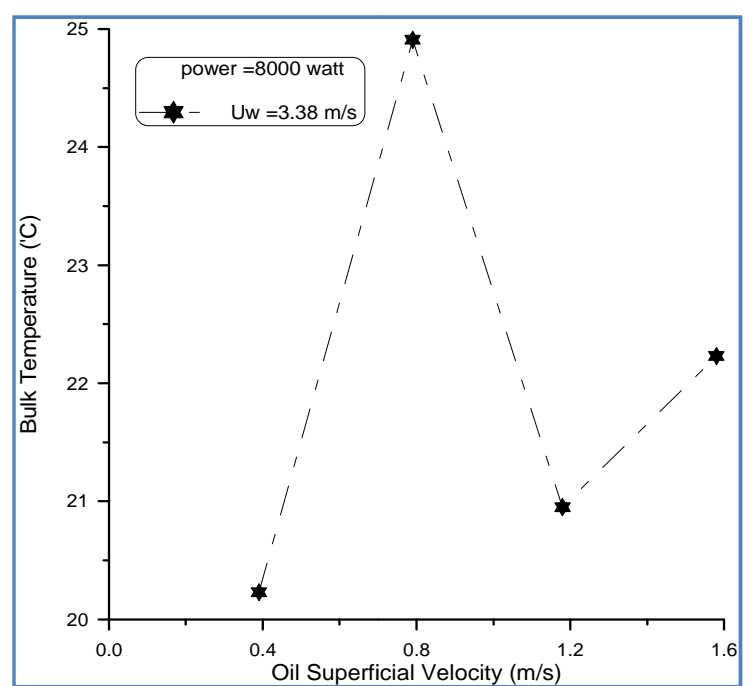

Fig. 20. Bulk Temperature versus oil superficial velocity.

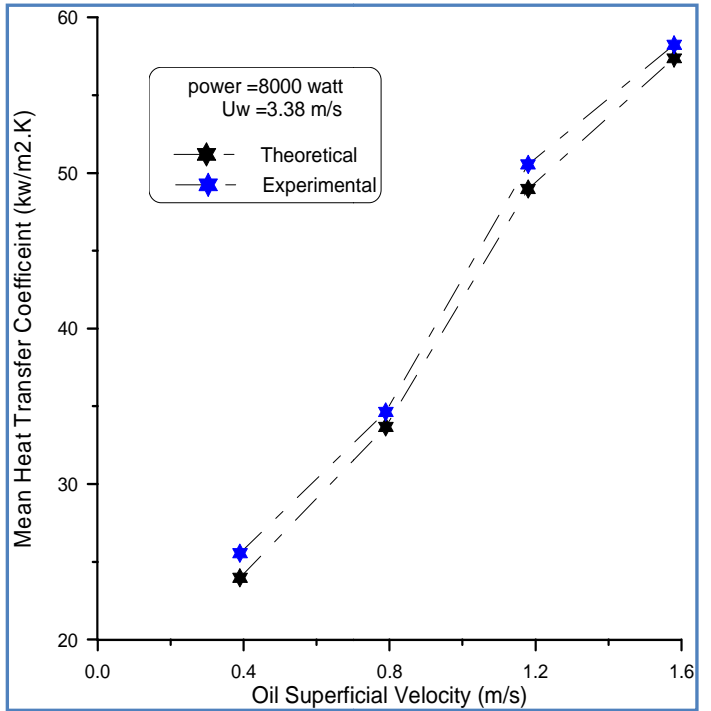

Fig. 21. Experimental and theoretical Mean Heat Transfer Coefficient comparison for oil-water flow at $U w=3.38 \mathrm{~m} / \mathrm{s}$.

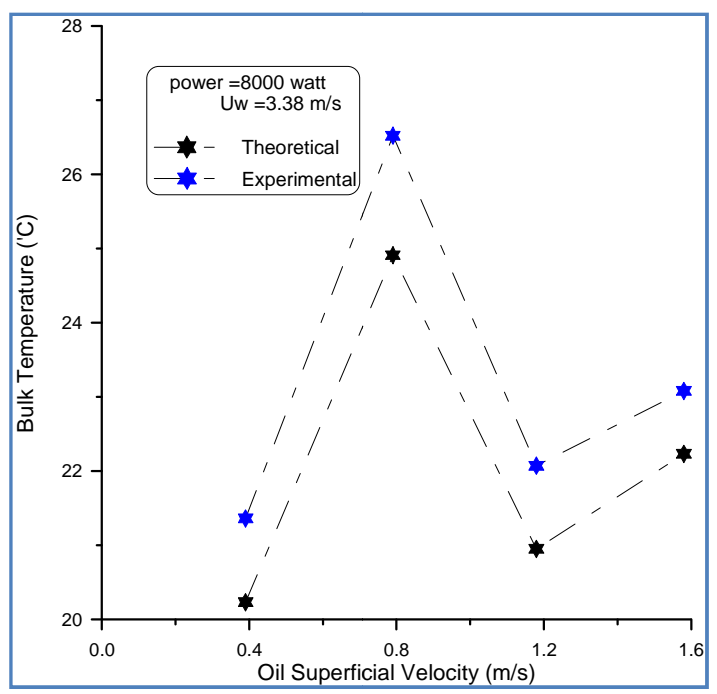

Fig. 22. Experimental and theoretical Bulk Temperature comparison for oilwater flow at $U w=3.38 \mathrm{~m} / \mathrm{s}$. 


\section{Nomenclature}

\begin{tabular}{|c|c|c|}
\hline$\Delta \mathrm{P}$ & $\begin{array}{l}\text { Pressure Gradient. } \\
\left(\mathrm{pa} / \mathrm{m}^{2}\right) \mathrm{A}\end{array}$ & Cross section area. $(\mathrm{m})$ \\
\hline $\mathrm{D}$ & Diameter. (m) & Do Oil Diameter. (m) \\
\hline Dw & Water Diameter. (m) & HL Holdup. (---) \\
\hline $\mathrm{L}$ & Length. (m) & Le $\begin{array}{l}\text { Entrance Length. } \\
(\mathrm{m})\end{array}$ \\
\hline Qo & Oil Flow Rate. $\left(\mathrm{m}^{3} / \mathrm{s}\right)$ & Qw $\begin{array}{l}\text { Water Flow Rate. } \\
\left(\mathrm{m}^{3} / \mathrm{s}\right)\end{array}$ \\
\hline $\operatorname{Re}$ & Reynolds no. (---) & Us $\begin{array}{l}\text { Superficial Velocity. } \\
(\mathrm{m})\end{array}$ \\
\hline L1 & Lighter liquid. & L2 heavier liquid \\
\hline CFD & $\begin{array}{l}\text { Computational Fluid } \\
\text { Dynamic. QCV }\end{array}$ & Quick-closing valve. \\
\hline VOF & Volume of Fluid. & $\begin{array}{l}\text { RGB:- Red, Green, and } \\
\text { Blue Image. }\end{array}$ \\
\hline $\mathrm{K}$ & Turbulence Kinetic En & ergy \\
\hline$\sigma_{\mathrm{k}}, \sigma_{\varepsilon}$ & Constants in the $\mathrm{k}-\varepsilon$ & model. \\
\hline$\varepsilon$ & Dissipation Rate. & $\lambda$ Input water cut. \\
\hline$\rho$ & Density. $\left(\mathrm{Kg} / \mathrm{m}^{3}\right)$ & $\begin{array}{ll}\alpha & \begin{array}{l}\text { Input volume } \\
\text { fraction. }\end{array}\end{array}$ \\
\hline$u$ & Viscosity. (kg/m.s) & Turbulence Intensity. \\
\hline
\end{tabular}

\section{References}

[1] Lawrence C. Edomwonyi-Otu, Panagiota Angeli*, " Pressure drop and holdup predictions in horizontaloil-water flows for curved and wavy interfaces", chemical engineering research and design, Cherd-1615, 2014.

[2] Russell, T.W.R. Hodgsen, G.W. and Govier, G.W., "Horizontal Pipeline Flow of Mixtures of Oil And Water," Can. Jornal Chem. Eng., Vol.37, pp.(9-17), 1959.

[3] Charles, M.E. and Redberger, P.J., "The Reduction of Pressure Gradients in Oil Pipelines by the addition of Water; Numerical Analysis of Stratified Flow" Chem. Eng., Vol.40, pp.(70-75), 1962.

[4] Glass, W., "Water Addition Aids Pumping Viscous Oils". Chem. Eng. Prog., Vol.57, pp.(116-118).

[5] Fujii, T., Otha, J., Nakazawa, T., and Morimoto, O., "The Behavior of an Immiscible Equal-Density Liquid-Liquid TwoPhase Flow in a Horizontal Tube", JSME Journal Series B,
Fluids and Thermal Engineering, Vol.30, No.1, PP.(22-29), 1994.

[6] M De Salve1, G Monni1 and B Panellal, "Horizontal AirWater Flow Analysis with Wire Mesh Sensor", Politecnico di Torino, Energy Department, C.so Duca degli Abruzzi 24, 10129 Torino, IT,pp.(177-182),2012.

[7] Guzhov, A., Grishin, A.D., Medredev, V.F. and Medredeva, O.P.: "Emulsion Formation during the Flow of Two Immiscible Liquids" Neft. Choz., Vol.8, pp.(58-61), 1973.

[8] Panagiota Angeli, Geoffrey F. Hewitt, "Pressure Drop Measurements in Oil and Water Prewetted Pipes", Department of Chemical and Biochemical Engineering, University College London, London, UK, 2011.

[9] R. Zimmerman, M. Gurevich, A. Mosyak, R. Rozenblit, G. Hetsroni," Heat transfer to air-water annular flow in a horizontal pipe", International Journal of Multiphase Flow, Vol.32, pp.(1-19), 2006.

[10] G. Hetsroni*, R. Rozenblit," Thermal patterns on a heated wall in vertical air-water flow", International Journal of Multiphase Flow, Vol.26, pp.(147-167), 2000.

[11] Manmatha K. Roula, Sukanta K. Dash." Flow of Single-Phase Water and Two-Phase Air-Water Mixtures through Sudden Contractions in Mini Channels", International Journal of Engineering Research and Applications (IJERA) ISSN, Vol. 2, Issue 5, pp.757-763,September- October 2012.

[12] Mohammed A. Al-Yaari* and Basel F. Abu-Sharkh," CFD Prediction of Stratified Oil-Water Flow in a Horizontal Pipe", Asian Transactions on Engineering (ATE), Vol.1, pp. (22214267), 2011.

[13] Holman, J.P., Gajda, W.J. "Experimental Methods for Engineers", McGraw-Hill Book Company, Fourth Edition, 1984.

[14] Ghajar, A. J., Tang, C.C, 2007, "Heat Transfer Measurements, Flow Pattern Maps, and Flow Visualization for Non-Boiling Two-Phase Flow in Horizontal and Slightly Inclined Pipe", J. Heat Transfer Engineering, Vol. 28, No. 6.

[15] Sylvester, N.D., Dowling, R.H., Mino, H.P., and Brill, J.P., " Drag Reduction in Two Phase Gas-Liquid Flow", Paper No. L11477e, University of Tulsa, January, 1997.

[16] Launder, B. and Spalding, D. "The Numerical Computation of Turbulent Flows", Computer Methods in Applied Mechanics and Engineering, Vol. 3, pp. (269-289), 1974. 